\title{
Estimating potential range shift of some wild bees in response to climate change scenarios in northwestern regions of Iran
}

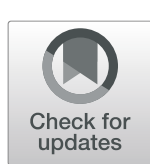

\author{
Ehsan Rahimi ${ }^{1 *} \mathbb{D}$, Shahindokht Barghjelveh and Pinliang Dong ${ }^{2}$
}

\begin{abstract}
Background: Climate change is occurring rapidly around the world, and is predicted to have a large impact on biodiversity. Various studies have shown that climate change can alter the geographical distribution of wild bees. As climate change affects the species distribution and causes range shift, the degree of range shift and the quality of the habitats are becoming more important for securing the species diversity. In addition, those pollinator insects are contributing not only to shaping the natural ecosystem but also to increased crop production. The distributional and habitat quality changes of wild bees are of utmost importance in the climate change era. This study aims to investigate the impact of climate change on distributional and habitat quality changes of five wild bees in northwestern regions of Iran under two representative concentration pathway scenarios (RCP 4.5 and RCP 8.5). We used species distribution models to predict the potential range shift of these species in the year 2070.

Result: The effects of climate change on different species are different, and the increase in temperature mainly expands the distribution ranges of wild bees, except for one species that is estimated to have a reduced potential range. Therefore, the increase in temperature would force wild bees to shift to higher latitudes. There was also significant uncertainty in the use of different models and the number of environmental layers employed in the modeling of habitat suitability.

Conclusion: The increase in temperature caused the expansion of species distribution and wider areas would be available to the studied species in the future. However, not all of this possible range may include high-quality habitats, and wild bees may limit their niche to suitable habitats. On the other hand, the movement of species to higher latitudes will cause a mismatch between farms and suitable areas for wild bees, and as a result, farmers will face a shortage of pollination from wild bees. We suggest that farmers in these areas be aware of the effects of climate change on agricultural production and consider the use of managed bees in the future.
\end{abstract}

Keywords: Iran, Wild bees, Pollination, Species distribution models, Climate change

\section{Introduction}

In recent years, the declining pollinator population has been a major concern globally (Viana et al. 2012), leading to more research on investigating pollinators' threatening factors and analyzing their reduction effects on agricultural and natural systems. Approximately, $88 \%$ of

\footnotetext{
* Correspondence: ehsanrahimi666@gmail.com

${ }^{1}$ Environmental Sciences Research Institute, Shahid Beheshti University, Tehran, Iran

Full list of author information is available at the end of the article
}

angiosperms (Ollerton et al. 2011) and 87 of the 115 most important food products require pollinators (Klein et al. 2007). Global temperatures are predicted to rise by an average of 2 to $4{ }^{\circ} \mathrm{C}$ by 2050 due to greenhouse gas emissions (Pachauri et al. 2014). These climate changes will shift the geographic distribution of pollinators and jeopardize food security in the future (Imbach et al. 2017). There are three possible scenarios related to species' responses to a regional climate change: (1) adaptation to new conditions, (2) migration to more suitable

(c) The Author(s). 2021 Open Access This article is licensed under a Creative Commons Attribution 4.0 International License, which permits use, sharing, adaptation, distribution and reproduction in any medium or format, as long as you give appropriate credit to the original author(s) and the source, provide a link to the Creative Commons licence, and indicate if changes were made. The images or other third party material in this article are included in the article's Creative Commons licence, unless indicated otherwise in a credit line to the material. If material is not included in the article's Creative Commons licence and your intended use is not permitted by statutory regulation or exceeds the permitted use, you will need to obtain permission directly from the copyright holder. To view a copy of this licence, visit http://creativecommons.org/licenses/by/4.0/. 
areas, and (3) extinction (Coope 1995). Although plantspollinators relationships have developed throughout the evolution process, the climate changes are happening at a faster pace, and the plants and pollinators cannot adapt to these changes (Yurk and Powell 2009). Since bees cannot fly during cold, windy, wet, and dark times, wild bees are more adaptable to future climatic conditions (Christmann and Aw-Hassan 2012). Rader et al. (2013) showed that under the worst scenario of climate change, pollination by honeybees would be reduced by $14.5 \%$, while native bee pollination will increase by $4.5 \%$ by 2099 .

Climate change can affect foraging activity, body size, and longevity of pollinating insects (Scaven and Rafferty 2013). For example, increasing the ambient temperature reduces the body size of bees (Schweiger et al. 2010). It is claimed that the effects of climate change on tropical insects are more significant because these species have narrow niches (i.e., they are specialist species that require very unique resources), and live in an environment that is close to their optimum temperature (Kjøhl et al. 2011). However, species that are at higher latitudes live at temperatures below their optimum temperature, consequently, increasing the temperature enhances the foraging activities of these species (Deutsch et al. 2008). Simulations show that 17 to $50 \%$ of pollinating insects are more likely to experience periods that do not access the floral resource for foraging due to the climate change effect (Memmott et al. 2007). The most important effect of climate change on the plants-pollinators relationship is temporal and spatial mismatches (Rafferty 2017; Schweiger et al. 2010). Early flowering plants seem to be less affected by climate change, and even in some cases benefit from climate change (Takkis et al. 2018). However, climate change effects can change the phenology of the early flowering plants (Karlík and Poschlod 2014). Rising temperatures negatively affect agricultural products at low latitudes while having a positive effect on products in high latitudes (Challinor et al. 2009). If bee foraging activity begins earlier than flowering time, survival rates and population size may decrease (Kjøhl et al. 2011). Moreover, the effects of climate change affect the spatial distribution of plants and pollinators, nectar quantity and quality, pollinator energy demand, plant community structure, and pollinator community structure (Schweiger et al. 2010).

To reduce the adverse effects of climate change on pollinators, it is essential to evaluate the effects of climate change on the distribution of pollinators (Polce et al. 2014). In this way, the methods that can correlate the current climate and pollinators' distribution can determine the areas that will be suitable for species in the future (Dew et al. 2019). Species distribution models (SDMs) are numerical tools that combine species presence points with environmental factors. In this type of model, the key assumption is that the species are in equilibrium with their environment (Elith and Leathwick 2009). As input, SDMs require georeferenced individual locations or species' presence as the response or dependent variable, and independent layers of environmental information such as climate, topographic slope, elevation, land cover, and soil attributes. The central idea of SDMs is the niche theory that was introduced by Joseph Grinell and G. Evelyn Hutchinson (Miller 2010). They distinguished two niches, namely, the fundamental niche and the realized niche. The fundamental niche encompasses all abiotic environmental conditions that a species is physiologically able to tolerate, while the realized niche comprises those parts of the fundamental niche where a species can survive despite the presence of competitors (Zurell et al. 2020). Therefore, the realized niche is geographically smaller than the fundamental niche due to negative interspecific interactions. Species niches are not only climate-related niches as many other environmental factors affect the presence of species and their habitat suitability. There are five main steps for SDM studies: conceptualization, data preparation, model fitting, model assessment, and prediction (Zurell et al. 2020).

Species distribution studies have shown that with increasing temperature, species distribution moves toward higher latitudes and polar regions (Hegland et al. 2009). Bumblebees, for instance, are cold-adapted species that have shifted to higher latitudes and mountain ecosystems over the past 100 years (Kerr et al. 2015; Ploquin et al. 2013; Pyke et al. 2016). In North America, the distribution models have shown that the diversity of Bombus species will decrease in southern regions in the future (Sirois-Delisle and Kerr 2018). Several studies have shown that the suitable habitats for wild bees will decrease due to future climate change (Giannini et al. 2012). For example, Suzuki-Ohno et al. (2020) claimed that the distribution range of five species of bumblebees has decreased after 26 years because of the climate change effect. Imbach et al. (2017) indicated that by 2055 , suitable areas for coffee will be reduced by $88 \%$. However, other studies have shown that rising temperature increases the suitable areas for bees. For example, in the case of carpenter bee species in Australia, Dew et al. (2019) found that climate change increased the suitability of this species. Besides, climate change reduces the overlap between suitable areas for horticultural and wild bee (Polce et al. 2014). For example, Bezerra et al. (2019) argued that climate change altered the natural range of Xylocopa bees as well as areas suitable for passion fruit production, resulting in a reduction in overlap areas between the two species. 
About $14.46 \%$ of Iran is covered by agricultural land, of which $54 \%$ is irrigated and $46 \%$ is rainfed farmlands. Approximately, $30 \%$ of Iran's agricultural products need pollinating insects. There are about 800 species of bees in Iran that belong to the families Colletidae, Halictidae, Andrenidae, Melittidae, Megachilidae, Anthophoridae, and Apidae (Mohammadian 2003). A wide range of pollinating bees has been recognized in different parts of Iran. Among them, two species of Apis florea and Apis mellifera meda have a wider distribution (Sanjerehei 2014). A. florea is distributed in southern parts of Iran and Apis mellifera meda has the most widespread distribution among other bees in the country (Rahimi and Mirmoayedi 2013). The economic value of pollination service in agricultural productions was estimated at $\$ 6.59$ billion in Iran in 2005-2006 (Sanjerehei 2014). $\$ 5.72$ billion was allocated to the honey bees and $\$ 0.87$ billion to the wild bees. It has been estimated that pollinators affect $25 \%$ of total agricultural products in Iran. To the best of our knowledge, no study has been conducted to model the effects of climate change on wild bees in Iran. Therefore, the present study aims to predict the future distributions of five wild bee species under climate change scenarios in northwestern regions of Iran.

\section{Material and methods \\ Study area}

From an ecological point of view, Iran is divided into three phytogeographical regions: the Euxino-Hyrcanian province of the Euro-Siberian region in the north, the Saharo- Sindian region in the south, and the IranoTuranian region in the western and central sectors of the country (Talebi et al. 2014). The study area in this study is located in two regions of Euxino-Hyrcanian and Irano-Turanian that also include the two mountain ranges of Alborz and Zagros. The area of the study area is $357090 \mathrm{~km}^{2}$ and mostly has a mountainous climate that is cold in winter and warm in summer (Fig. 1).

\section{Species occurrence data and environmental predictors}

In this study, we used presence-only records of five wild bee species belonging to three families available at the Global Biodiversity Information Facility (GBIF) website (www.gbif.org). These species are Halictus

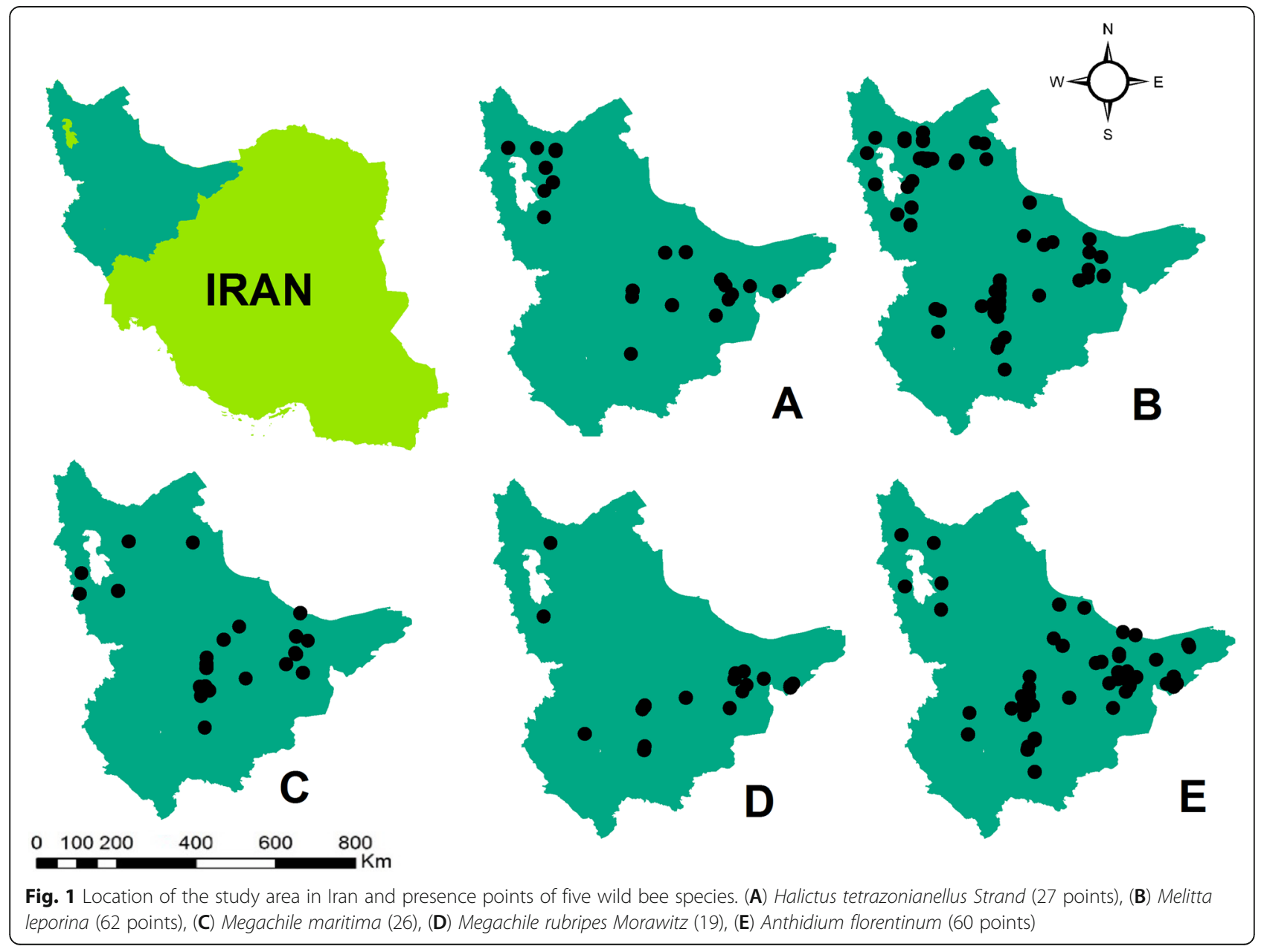


tetrazonianellus Strand (Halictidae), Melitta leporina (Melittidae), Megachile maritima, Megachile rubripes Morawitz, and Anthidium florentinum (Megachilidae), and their spatial distributions are shown in Fig. 1. Melitta leporina is one of the solitary bees that nest in the ground and the maximum foraging distances of this species in alfalfa fields are estimated to be 25 to $30 \mathrm{~cm}$. Melitta leporina is the most common species among the 17 members of the genus Melitta and is found throughout Europe and around the Caspian Sea, Iran, and Kazakhstan (Celary 2006). Megachile maritima is on the IUCN red list in Germany, the Netherlands, and Ireland. This species is polylectic and collects pollen mostly from the Asteraceae and Rosaceae families (Güler and Bursali 2008). Anthidium florentinum is a solitary bee the size of a honeybee. It is widespread in northern Africa, Europe, and Asia and has been introduced to the USA. Females nest in pre-existing cavities and cover the cavities with leaves (Wirtz et al. 1992). Megachile rubripes Morawitz is a leaf-cutter bee that is found in the northern and southern regions of Iran and is associated with the Asteraceae and Lamiaceae families (Samin et al. 2015). Halictus tetrazonianellus Strand is spread in Iran, Turkey, Azerbaijan, Lebanon, and northern Russia that is associated with the Asteraceae families (Dikmen and Aytekin 2011). We chose these species to compare the effects of climate change on those that nest in the ground (Halictus tetrazonianellus Strand and Melitta leporina) and those that are above-ground nesting and nest in cavities (Megachile maritima, Megachile rubripes Morawitz, and Anthidium florentinum).

The bioclimatic variables as environmental predictors were obtained from the WorldClim database (www. worldclim.org). The WorldClim data layers included 11 temperature and eight precipitation metrics with a spatial resolution of about $1 \mathrm{~km}^{2}$. Layers with a correlation greater than 0.8 were excluded from the modeling process, and finally, layers including isothermality (Bio3), temperature seasonality (Bio4), maximum temperature of the warmest month (Bio5), minimum temperature of the coldest month (Bio6), mean temperature of the wettest quarter (Bio8), mean temperature of warmest quarter (Bio10), annual precipitation (Bio12), and precipitation seasonality (Bio15) were selected. We modeled the future possible distribution of all five species under two representative concentration pathway scenarios (RCP 4.5 and RCP 8.5) in the year 2070. Scenarios RCP 4.5 and RCP 8.5 are known as moderate and worst scenarios where the average Earth temperature rises from 1.4 to $1.8{ }^{\circ} \mathrm{C}$ for the moderate scenario and 2 to $3.7^{\circ} \mathrm{C}$ for the worst scenario (Stocker et al. 2014).

\section{Species distribution modeling}

According to response variables, species distribution models are divided into two categories: discrimination and profiles. Discrimination models require the presence and absence records of the species of interest and perform the modeling process based on the correlation between species records and environmental variables. Discrimination models are divided into two categories: global (parametric) and local (non-parametric) (Tarkesh and Jetschke 2012). Global models include generalized linear models (GLM), multiple logistic regression (MLR), Gaussian logistic regression (GLR), logistic regression (LR), and artificial neural network (ANN). Local models include generalized additive model (GAM), classification and regression tree model (Milano et al., 2019), nonparametric multiplicative regression (NPMR), logistic regression tree (LRT), random forest (RF), and boosted regression tree (BRT). In contrast, profile models use species presence-only data to model the possible distribution of species (Miller 2010). These models including BIOCLIM, DOMAIN, and maximum entropy (MAXENT), and ecological niche factor analysis.

In this study, we used the SDM software package (Naimi et al. 2016) in $\mathrm{R}$ for modeling potential native bee distribution. To achieve this, we used three classification models including RF, CART, BRT, and two regression models including GLM and GAM to create habitat suitability maps based on climate data. For predicting possible future distributions under RCP 4.5 and RCP 8.5 in the year 2017, we used the RF model because it showed higher performance than other models evaluated in the current study (see the "Results" section).

Random forest (RF) models are among the machine learning methods that provide a single prediction by ensembling several poorly predicted models. This algorithm creates a forest randomly. The constructed forest is a set of "Decision Trees." The construction of the forest using trees is often done by the method of "bagging." The main idea of the bagging method is that a combination of learning models enhances the overall results of the model. Simply, a random forest makes several decision trees and combines them to make more accurate and consistent predictions. This model creates a large number of decision trees and then combines all the trees for the final prediction of the most parsimonious species distribution. The RF model split the predictor variable based on the homogeneity of the responses. Each split point divides the response into two nodes so that there is maximum similarity within the nodes, and minimal similarity between the nodes (Valavi et al. 2020). The number of trees and the number of predictor variables are the key parameters of the random forest model (Jafarian et al. 2019). The high efficiency of the random forest method has been confirmed by many studies (Bradter et al. 2013; Cushman and Wasserman 2018; Rather et al. 2020), especially when the presence points are limited (Strobl et al. 2007). 
The CART algorithm creates a decision tree with binary divisions. It tests the input variables to find the best split so that the impurity index (Gini) resulting from the splitting has the lowest value. In the analysis, two subsets are split based on homogeneous values of the dependent variable and each is split into two other subgroups in the next step using the same approach, and the process continues repeatedly (Jafarian et al. 2019). As the tree grows, the nodes become more homogeneous, and more information becomes visible. Eventually, the splitting process stops due to a lack of data.

The boosted regression tree (BRT) is an ensemble of statistical techniques and machine learning. This model is one of the techniques that improve the performance of a single model by using a combination of multiple models. This model combines the strengths of two algorithms: CART and boosting. Boosting is a way to increase the accuracy of a model, and the basis of its work is that building, combining, and averaging a large number of models is better than creating a model (Elith et al. 2008). The basic idea in this model is to combine a set of weak predictive models to achieve a strong prediction.

The generalized linear model (GLM) is an example of a linear regression model that estimates the statistical relationship between a response variable and one or more predictor variables (Guisan et al. 2002). This model is one of the parametric models and is used for cases where the observations are not normally distributed and other regression models are not suitable. This model has been developed to reduce limiting assumptions in linear regression and can be fitted for a range of distributions (Binomial, Poisson, Gaussian, Bernoulli, Gamma, etc.).

The generalized additive (GAM) model is a nonparametric model and an extension of generalized linear models. The generalized additive model provides a suitable method for analyzing data and examining the relationship between dependent and independent variables (Kosicki 2020). Generalized additive models (GAM) are superior to generalized linear models (GLM) in several respects and the purpose of using these models is to maximize the predictive quality of the dependent variable, to discover non-linear relationships between the dependent variable, and the set of explanatory variables. Unlike the generalized linear model, in which the relationship between explanatory variables and response is represented by a formula, the data are allowed to determine the shape of the response curve.

Most ecological niche models use presence and absence data for modeling. It is very difficult to obtain species absence data because it requires a lot of sampling effort in the study area. Background points are samples that are randomly extracted from the study area to be used along with presence data for modeling species presence-only data. The central idea of the pseudo- absences points is to allow species distribution models to compare the desired regions for the species to other regions throughout the study area (Valavi et al. 2020). Furthermore, background points are used to quantify environmental conditions in the region of interest, so the number of required points differs depending on the complexity of environments in the region (Renner et al. 2015). Barbet-Massin et al. (2012) recommended the use of a large number of pseudo-absences in using regression models like generalized linear models (GLM) and generalized additive models. For classification techniques such as random forest (RF), boosted regression trees (BRT), and classification trees, they recommend using the same number of available presence data for pseudoabsences. Therefore, we selected 10000 random points from the background as the pseudo-absence points for GLM and GAM models and generated the same number of presence data from the background as pseudoabsences data for classification models like RF, CART, and BRT.

\section{Model assessment}

We evaluated the model performance using 10 runs of subsampling replications by randomly splitting our occurrence data into $70 \%$ as training data and $30 \%$ as test data. Two statistics, true skill statistic and the area under the ROC curve (AUC), were used to verify the model performance. Models with AUC values of 0.7-0.9 are acceptable, whereas the values higher than 0.9 are regarded as models with excellent abilities. TSS ranges from -1 to +1 , where +1 indicates perfect classification, and values between 0.4 to 0.6 show a moderate performance of the model. The suitability maps derived from SDMs range from 0 to 1 , with the number one indicating the maximum suitability for the species. In this study, suitability maps were divided into three categories: high (0.7-1), moderate (0.3-0.7), and low (0-0.3), so that changes in species distribution range under climate change scenarios would be quantified.

\section{Uncertainty and sensitivity analysis}

Uncertainty can be present in different steps of the implementation of species distribution models. Accurate coordinate recording and spatial autocorrelation between absence/presence data in the first step, type and the number of environmental layers, and the correlation between them, spatial extent and grain size of raster layers in the second step, and the selection of different algorithms for modeling habitat suitability maps in the last step are cases that cause uncertainty in SDMs (Fernández et al. 2013). In this study, five models including RF, CART, BRT, GLM, and GAM were used to show the uncertainties associated with species distribution models. Different algorithms produced different results, 
so we used the mentioned models to provide habitat suitability maps only in the current scenario and compared the results of the models. From these models, we determined the most efficient algorithm according to AUC and TSS statistics and predicted the effects of climate change on the possible future distribution of wild bees under two RCPs in the year 2070.

To perform sensitivity analysis, first, we estimated the relative contribution of the environmental layers for the five mentioned algorithms for species under study. Then, we removed the environmental layer that had the highest contribution in the modeling process and again produced a new habitat suitability map to determine the effect of removing one layer or the most important layer on the results. Sensitivity analysis was performed only for the most efficient algorithm (i.e., random forest).

\section{Results}

Evaluations of the models and the relative contribution of variables

Table 1 shows the results of the model performance using TSS and AUC statistics. In this table, the items with the highest mean of AUC and TSS are bolded. AUC and TSS for RF model are AUC $=0.8 \pm 0.04$; TSS $=0.53 \pm 0.1 ; \mathrm{AUC}=0.76 \pm 0.08 ; \mathrm{TSS}=0.46 \pm 0.1 ; \mathrm{AUC}$ $=0.85 \pm 0.04 ; \mathrm{TSS}=0.68 \pm 0.05 ; \mathrm{AUC}=0.82 \pm 0.05$; $\mathrm{TSS}=0.61 \pm 0.06 ;$ AUC $=0.86 \pm 0.04 ;$ TSS $=0.66 \pm$ 0.07 for Melitta leporina (ML), Megachile maritima (MM), Halictus tetrazonianellus Strand (HT), Anthidium florentinum (AF), and Megachile rubripes Morawitz respectively. AUC statistic shows that the random forest method has the highest performance for all species than other models. However, the TSS statistic shows moderate efficiency for the random forest method in determining the habitat suitability map for Melitta leporina and Megachile maritima species. For this reason, we used only the random forest (RF) model to predict the possible future distribution of bees under climate change scenarios.

Table 2 shows estimates of relative contributions of the predictor environmental variables to RF, CART,

Table 1 Model validation metrics including TSS and AUC for each species. Melitta leporina (ML), Megachile maritima (MM), Halictus tetrazonianellus Strand (HT), Anthidium florentinum (AF), Megachile rubripes Morawitz

\begin{tabular}{|c|c|c|c|c|c|c|c|c|c|c|}
\hline & \multicolumn{2}{|l|}{$\mathrm{RF}$} & \multicolumn{2}{|l|}{ GLM } & \multicolumn{2}{|l|}{ GAM } & \multicolumn{2}{|l|}{ BRT } & \multicolumn{2}{|l|}{ CART } \\
\hline & $\overline{A U C}$ & & $\overline{A U C}$ & TSS & $\overline{A U C}$ & TSS & $\overline{A U C}$ & $\overline{T S S}$ & $\overline{A U C}$ & TSS \\
\hline $1 \mathrm{~L}$ & & 0.53 & & 0.39 & & 0.41 & & 0.52 & 0.7 & 0.4 \\
\hline MM & & & & 0.21 & 0.62 & 0.3 & 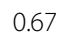 & 0.4 & 0.6 & 0.26 \\
\hline & & & 0.65 & 0.38 & & 0.26 & 0.7 & 0.46 & 0.61 & 0.27 \\
\hline & 0.82 & 0.61 & 0.57 & 0.29 & 0.68 & 0.4 & 0.79 & 0.55 & 0.73 & 0.44 \\
\hline IR & 0.86 & 0.66 & 0.62 & 0.4 & 0.63 & 0.33 & 0.72 & 0.55 & 0.65 & 0.38 \\
\hline
\end{tabular}

BRT, GLM, and GAM models. According to this table, RF, CART, BRT, and GAM models show Bio3 as the most effective layer in the habitat suitability modeling process for Melitta Leporina (ML). However, GLM indicated Bio6 as the most effective layer. For Megachile Maritima (MM), Bio6 had the highest contribution in RF, BRT, and GLM models. Bio4 and Bio18 were considered as layers with the highest impact in habitat modeling in GAM and CART models respectively. Halictus Tetrazonianellus Strand (HT), GAM model indicated Bio18 as the most effective layer and in others, Bio3 had the highest importance in the habitat suitability modeling process. For Anthidium Florentinum (AF), RF and BRT models showed Bio12, GLM, GAM, and CART indicated Bio5, Bio15, and Bio18 as the most effective layer respectively. For Megachile Rubripes Morawitz, Bio3 had the highest contribution in RF and CART models. GLM, GAM, and BRT models showed Bio12, Bio5, and Bio8 as layers with the highest importance in the modeling process.

\section{Uncertainty and sensitivity analysis}

Table 3 shows the area and percentage of different classes of habitat suitability maps for different models and species. The results of this table show that different algorithms have different results for each species. For example, for Melitta leporina (ML), BRT has modeled only two classes with low and moderate suitability, but other models have considered an average of $5 \%$ of the study area in the high suitability class. RF and GAM models have shown similar results. Megachile maritima (MM), different models have also shown different results, so that the CART model has considered about $10 \%$ of the study area as a high-suitability class, while the BRT and GLM models have shown only two classes of low and moderate suitability. For other species, this difference can be seen in the area and proportions of habitat suitability classes obtained from different models. Table 3 shows that there are significant uncertainties in the use of different models that can lead to misleading results.

Sensitivity analysis of the results of the random forest model was performed based on the removal of the environmental layer, which had the highest relative participation in habitat modeling. For Melitta leporina (ML), Halictus tetrazonianellus Strand (HT), and Megachile rubripes Morawitz, Bio3 was the most effective layer in the habitat suitability modeling. For Megachile Maritima (MM) and Anthidium florentinum (AF), Bo6 and Bio12 were the layers with the highest impact on the modeling process. Table 4 shows that the removal of the most effective environmental layer from the modeling process has a significant impact on the results of the random forest model. For Anthidium florentinum (AF), for example, with the removal of Bio12, about $6 \%$ of the study 
Table 2 Estimates of relative contributions of the predictor environmental variables to the RF, CART, BRT, GLM, and GAM models. Melitta leporina (ML), Megachile maritima (MM), Halictus tetrazonianellus Strand (HT), Anthidium florentinum (AF), Megachile rubripes Morawitz

\begin{tabular}{|c|c|c|c|c|c|c|c|c|c|}
\hline Species & Model & Bio3 & Bio4 & Bio5 & Bio6 & Bio8 & Bio12 & Bio15 & Bio18 \\
\hline \multirow[t]{5}{*}{$\overline{M L}$} & RF & $10.4 \%$ & $5.3 \%$ & $1.1 \%$ & $2.9 \%$ & $1.7 \%$ & $5.1 \%$ & $2.3 \%$ & $4.2 \%$ \\
\hline & GLM & $7.5 \%$ & $17.5 \%$ & $15.8 \%$ & $27.7 \%$ & $20.4 \%$ & $1.1 \%$ & $8 \%$ & $6.4 \%$ \\
\hline & GAM & $18.2 \%$ & $13.2 \%$ & $14.7 \%$ & $31 \%$ & $6.1 \%$ & $4.8 \%$ & $15.3 \%$ & $11.15 \%$ \\
\hline & BRT & $14.5 \%$ & $3.3 \%$ & $1.5 \%$ & $9.9 \%$ & $4.6 \%$ & $2.6 \%$ & $1.9 \%$ & $7.3 \%$ \\
\hline & CART & $20.4 \%$ & $2.2 \%$ & $5.4 \%$ & $7.6 \%$ & $5.8 \%$ & $7 \%$ & $0.6 \%$ & $9 \%$ \\
\hline \multirow[t]{5}{*}{ MM } & RF & $5.9 \%$ & $6.9 \%$ & $5.9 \%$ & $10.1 \%$ & $2.7 \%$ & $4.5 \%$ & $7.4 \%$ & $8.8 \%$ \\
\hline & GLM & $6.3 \%$ & $12.1 \%$ & 7.85 & $14.6 \%$ & $2.3 \%$ & $3.1 \%$ & $7.6 \%$ & $12.4 \%$ \\
\hline & GAM & $15.6 \%$ & $21.3 \%$ & $16.4 \%$ & $13.9 \%$ & $2.4 \%$ & $11.4 \%$ & $23.5 \%$ & $16.8 \%$ \\
\hline & BRT & $8.3 \%$ & $1.5 \%$ & $6.2 \%$ & $13.1 \%$ & $3.1 \%$ & $5.9 \%$ & $5.4 \%$ & $11.8 \%$ \\
\hline & CART & $8.1 \%$ & $1.1 \%$ & $7 \%$ & $12.1 \%$ & $1.2 \%$ & $6.8 \%$ & $3.8 \%$ & $10 \%$ \\
\hline \multirow[t]{5}{*}{ HT } & RF & $12.7 \%$ & $5.7 \%$ & $3.2 \%$ & $2.3 \%$ & $2.1 \%$ & $7.1 \%$ & $10.1 \%$ & $5.9 \%$ \\
\hline & GLM & $25 \%$ & $9.1 \%$ & $10.1 \%$ & $18.1 \%$ & $1.4 \%$ & $20.3 \%$ & $19.4 \%$ & $9.5 \%$ \\
\hline & GAM & $8.5 \%$ & 14.65 & $14 \%$ & $9.8 \%$ & $2.7 \%$ & $9.2 \%$ & $14.5 \%$ & $15.2 \%$ \\
\hline & BRT & $16 \%$ & $1.5 \%$ & $2.5 \%$ & $0.9 \%$ & $0.5 \%$ & $12.1 \%$ & $6.7 \%$ & $2 \%$ \\
\hline & CART & $22.8 \%$ & $0.9 \%$ & $3.2 \%$ & $1.4 \%$ & $0.9 \%$ & $11.1 \%$ & $2 \%$ & $0.5 \%$ \\
\hline \multirow[t]{5}{*}{$\mathrm{AF}$} & RF & $1.7 \%$ & $1.9 \%$ & $1.2 \%$ & $2.1 \%$ & $5.6 \%$ & $15.1 \%$ & $6.2 \%$ & $5.5 \%$ \\
\hline & GLM & $12.8 \%$ & $7.5 \%$ & $13.5 \%$ & $9 \%$ & $8.8 \%$ & $8.5 \%$ & $3.2 \%$ & $1.8 \%$ \\
\hline & GAM & $8.9 \%$ & $10.7 \%$ & $17.4 \%$ & $12.2 \%$ & $9.4 \%$ & $3.6 \%$ & $28.5 \%$ & $8.3 \%$ \\
\hline & BRT & $1.6 \%$ & $1.2 \%$ & $1.2 \%$ & $2.3 \%$ & $4.3 \%$ & $16.6 \%$ & $5.2 \%$ & $8 \%$ \\
\hline & CART & $4.6 \%$ & $4 \%$ & $1.4 \%$ & $7.7 \%$ & $9 \%$ & $33.6 \%$ & $4.7 \%$ & $14.9 \%$ \\
\hline \multirow[t]{5}{*}{ MR } & $\mathrm{RF}$ & $14.7 \%$ & $1.9 \%$ & $5.2 \%$ & $1.9 \%$ & $11.2 \%$ & $6.8 \%$ & $3.3 \%$ & $5.6 \%$ \\
\hline & GLM & $15.4 \%$ & $12.2 \%$ & $26 \%$ & $13.4 \%$ & $25 \%$ & $22.7 \%$ & $6.4 \%$ & $8.6 \%$ \\
\hline & GAM & $23.4 \%$ & $15.3 \%$ & $23.8 \%$ & $15.8 \%$ & $14.3 \%$ & $10.6 \%$ & $10.9 \%$ & $9.8 \%$ \\
\hline & BRT & $7.5 \%$ & $0.5 \%$ & $2.3 \%$ & $0.8 \%$ & $16.1 \%$ & $15.7 \%$ & $0.7 \%$ & $2 \%$ \\
\hline & CART & $22.8 \%$ & $2.1 \%$ & $2.4 \%$ & $2 \%$ & $17.3 \%$ & $12.2 \%$ & $2.5 \%$ & $2.1 \%$ \\
\hline
\end{tabular}

area is considered in the high-suitability class, while Table 3 showed that in the case where no layer was removed, the RF model only showed two classes with moderate and low suitability. For other species, the removal of the most important layer has less effect on the results of the RF model.

\section{Possible future distributions based on the random forest model}

Since the model assessment results showed that the random forest model had the highest performance among all models, we only used this model to predict the possible future distribution of bees under climate change scenarios.

Figure 2 shows the habitat suitability maps for the present (row A) and the year 2070 under scenarios RCP 4.5 (row B) and RCP 8.5 (row C). In this figure, the habitat suitability is between 0 and 1 , and numbers close to one indicate a high degree of suitability. According to this figure, it can be seen that the species under study can mainly occupy a small area of the study area potentially at present. However, as time goes on and the temperature of the area rises, it can be seen that a large area of the study area will be favorable for wild bees and the distribution of the species will shift to higher latitudes. The highest rate of the shift in distribution can be observed for Halictus tetrazonianellus Strand, which under a scenario of RCP 8.5 covers a large area of the study area.

Figure 3 shows the classification maps of habitat suitability in high, moderate, and low classes. This figure shows the current maps (row A), scenarios 4.5 (row B), and 8.5 (row $\mathrm{C}$ ). According to this figure, it can be seen that with increasing temperature in scenarios RCP 4.5 and RCP 8.5 , the range of the suitable areas for the species under study will increase, and their distribution will be shifted to higher latitudes. This increase is more significant for Halictus tetrazonianellus Strand, Anthidium florentinum, and Megachile maritima. For Melitta leporina, the range of suitable areas will decrease with 
Table 3 Area and proportions of different classes of habitat suitability maps of the RF, CART, BRT, GLM, and GAM models for five species including Melitta leporina (ML), Megachile maritima (MM), Halictus tetrazonianellus Strand (HT), Anthidium florentinum (AF), Megachile rubripes Morawitz

\begin{tabular}{|c|c|c|c|c|c|c|c|}
\hline Species & Model & High (Ha) & Proportion & Moderate (Ha) & Proportion & Low (Ha) & Proportion \\
\hline \multicolumn{8}{|l|}{$\overline{M L}$} \\
\hline & RF & 1943932 & $5.44 \%$ & 21339347 & $59.72 \%$ & 12448757 & $34.83 \%$ \\
\hline & GLM & 392093 & $1.09 \%$ & 18619115 & $52.06 \%$ & 16747625 & $46.84 \%$ \\
\hline & GAM & 1998060 & $5.58 \%$ & 14410090 & $40.29 \%$ & 19350621 & $54.12 \%$ \\
\hline & BRT & - & - & 19848746 & $55.50 \%$ & 15910047 & $45.50 \%$ \\
\hline & CART & 2927952 & $8.18 \%$ & 10543384 & $29.48 \%$ & 22287472 & $62.33 \%$ \\
\hline \multicolumn{8}{|l|}{ MM } \\
\hline & RF & 52833 & $0.14 \%$ & 4515188 & $12.63 \%$ & 31164039 & $87.21 \%$ \\
\hline & GLM & - & - & 2462414 & $6.88 \%$ & 33296429 & $93.11 \%$ \\
\hline & GAM & 2553263 & $7.14 \%$ & 8523604 & $23.83 \%$ & 24681893 & $69.02 \%$ \\
\hline & BRT & - & - & 1585508 & $4.43 \%$ & 34173334 & $95.56 \%$ \\
\hline & CART & 3484035 & $9.73 \%$ & 8997875 & $25.16 \%$ & 23276918 & $65.10 \%$ \\
\hline \multicolumn{8}{|l|}{ HT } \\
\hline & RF & 40051 & $0.11 \%$ & 2938465 & $8.22 \%$ & 32753537 & $91.66 \%$ \\
\hline & GLM & 2995408 & $8.37 \%$ & 12236867 & $34.22 \%$ & 20526498 & $57.40 \%$ \\
\hline & GAM & 2821951 & $7.89 \%$ & 9261979 & $25.90 \%$ & 23674844 & $66.20 \%$ \\
\hline & BRT & - & - & 2089083 & $5.84 \%$ & 33669716 & $94.15 \%$ \\
\hline & CART & 816949 & $2.28 \%$ & 5483838 & $15.33 \%$ & 29457997 & $82.37 \%$ \\
\hline \multicolumn{8}{|l|}{ AF } \\
\hline & RF & - & - & 6950913 & $19.45 \%$ & 28781143 & $80.54 \%$ \\
\hline & GLM & 768657 & $2.14 \%$ & 23233406 & $64.97 \%$ & 11756815 & $32.88 \%$ \\
\hline & GAM & 5012803 & $14 \%$ & 7833518 & $21.90 \%$ & 22912471 & $65 \%$ \\
\hline & BRT & - & - & 18552795 & $51.88 \%$ & 17206014 & $48.12 \%$ \\
\hline & CART & 2488681 & $6.95 \%$ & 7181425 & $20.08 \%$ & 26088729 & $72.95 \%$ \\
\hline \multicolumn{8}{|l|}{ MR } \\
\hline & RF & 166248 & $0.46 \%$ & 1639611 & $4.58 \%$ & 33926212 & $94.94 \%$ \\
\hline & GLM & 205012 & $0.57 \%$ & 5621223 & $15.71 \%$ & 29932597 & $83.70 \%$ \\
\hline & GAM & 1014423 & $2.83 \%$ & 4741341 & $13.25 \%$ & 30003099 & $83.92 \%$ \\
\hline & BRT & - & - & 906939 & $2.53 \%$ & 34851885 & $97.47 \%$ \\
\hline & CART & 293212 & $0.81 \%$ & 21950422 & $61.38 \%$ & 13515205 & $37.97 \%$ \\
\hline
\end{tabular}

increasing temperature. It is noteworthy that the high suitability class for all species in scenarios RCP 4.5 and RCP 8.5 has disappeared, and only two classes (moderate and low) have remained.

Table 5 shows the area and percentage of habitat suitability classes under scenarios 4.5 and 8.5. According to this table, the range of suitable areas for four species will increase with increasing temperature in 2070 under RCP 4.5 and 8.5. For Melitta leporina, with increasing temperature, the range of suitable areas will decrease in 2070. It is noteworthy that for Melitta leporina, under both scenarios, the high-suitability class will disappear and the area of the moderate class will reduce by $20 \%$. For Megachile maritima under both scenarios, the area of parts with moderate suitability will increase by $20 \%$ and the class with high suitability will disappear. For Halictus tetrazonianellus Strand, the class with high suitability will disappear in the year 2070 and the area of the class with moderate suitability will increase by $38 \%$ under RCP 4.5 and 42\% under RCP 8.5. For Anthidium florentinum, no high-suitability class was identified for the current scenario, but in 2070, the area of the moderate class will increase by $12 \%$ under RCP 4.5 and $6 \%$ under RCP 8.5. For Megachile rubripes Morawitz, the high-suitability class will disappear with increasing temperature in the year 2070, and the area of the moderate class will increase by $8 \%$ and $6 \%$ under RCP 4.5 and RCP 8.5 respectively. 
Table 4 Sensitivity analysis based on the removal of the environmental layer that had the highest impact on the habitat suitability modeling

\begin{tabular}{|c|c|c|c|c|c|c|c|}
\hline Species & Layer & High (Ha) & Proportion & Moderate (Ha) & Proportion & Low $(\mathrm{Ha})$ & Proportion \\
\hline \multicolumn{8}{|l|}{$\mathrm{ML}$} \\
\hline & Bio3 & 784250 & $2.19 \%$ & 16987819 & $47.50 \%$ & 17986728 & $50.30 \%$ \\
\hline \multicolumn{8}{|l|}{ MM } \\
\hline & Bio6 & 106402 & $0.29 \%$ & 7909603 & $22.11 \%$ & 27742817 & $22.4 \%$ \\
\hline \multicolumn{8}{|l|}{ HT } \\
\hline & Bio3 & 16655 & $0.04 \%$ & 4551110 & $12.72 \%$ & 31191026 & $87.22 \%$ \\
\hline \multicolumn{8}{|l|}{ AF } \\
\hline & Bio12 & 2145484 & $5.99 \%$ & 9596870 & $26.83 \%$ & 24016427 & $67.16 \%$ \\
\hline \multicolumn{8}{|l|}{ MR } \\
\hline & $\mathrm{Bio} 3$ & 32194 & $0.09 \%$ & 3039654 & $8.50 \%$ & 32686989 & $91.40 \%$ \\
\hline
\end{tabular}

In general, our results showed that with the increase in temperature in 2070 under two scenarios, RCP 4.5 and RCP 8.5, the area of suitable classes for wild bees will increase, but this increase will occur only in the moderate class, and the high-suitability class will disappear. For one species, increasing the temperature will reduce the desired areas for it.

\section{Discussion}

Our results showed that with increasing temperature under scenarios RCP 4.5 and RCP 8.5, the possible distribution of wild bees would shifted to higher latitudes. This result has been reported by other studies. For example, bumblebees have been reported to shift to higher latitudes over the past 100 years (Kerr et al. 2015; Pyke

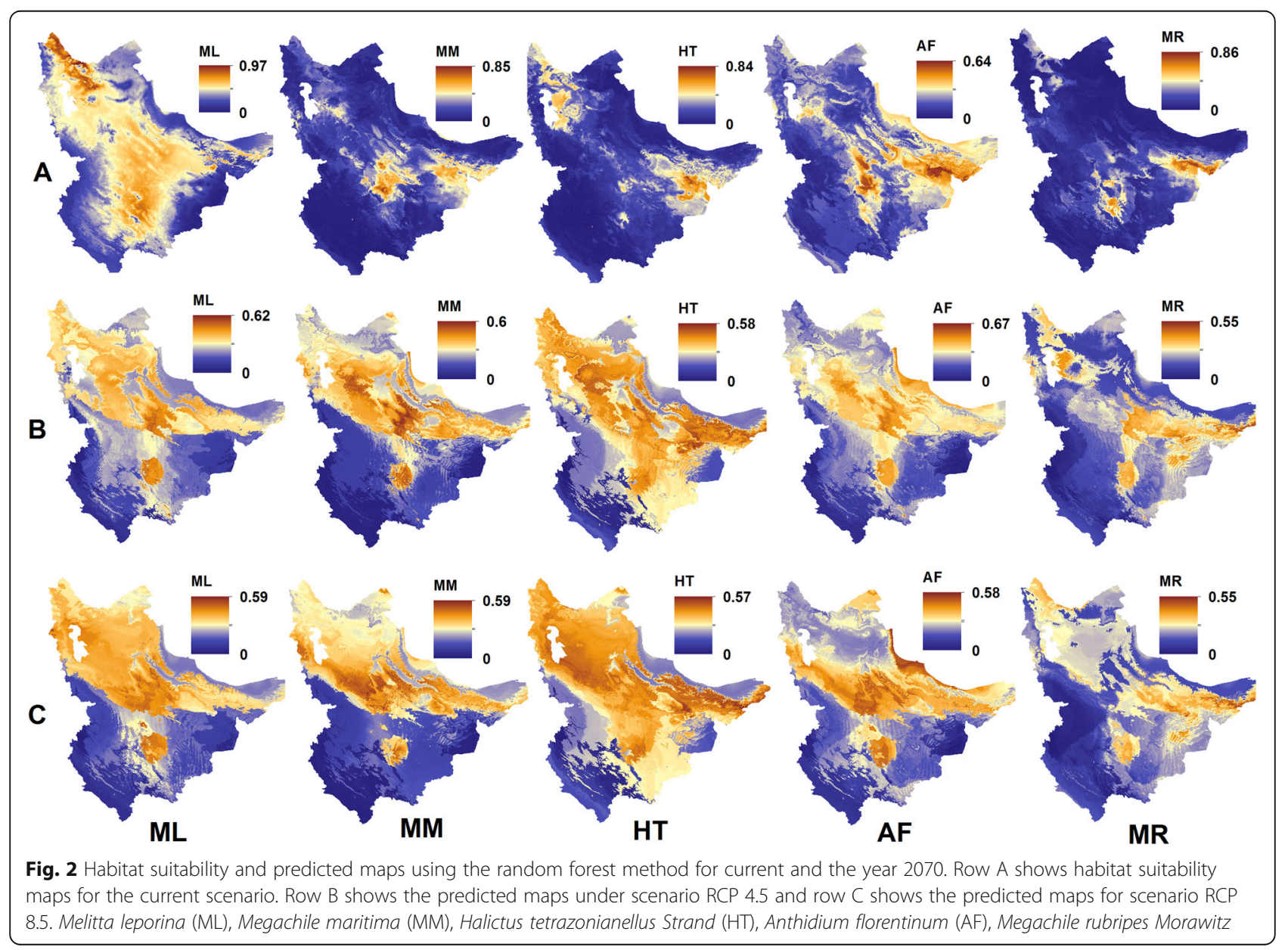




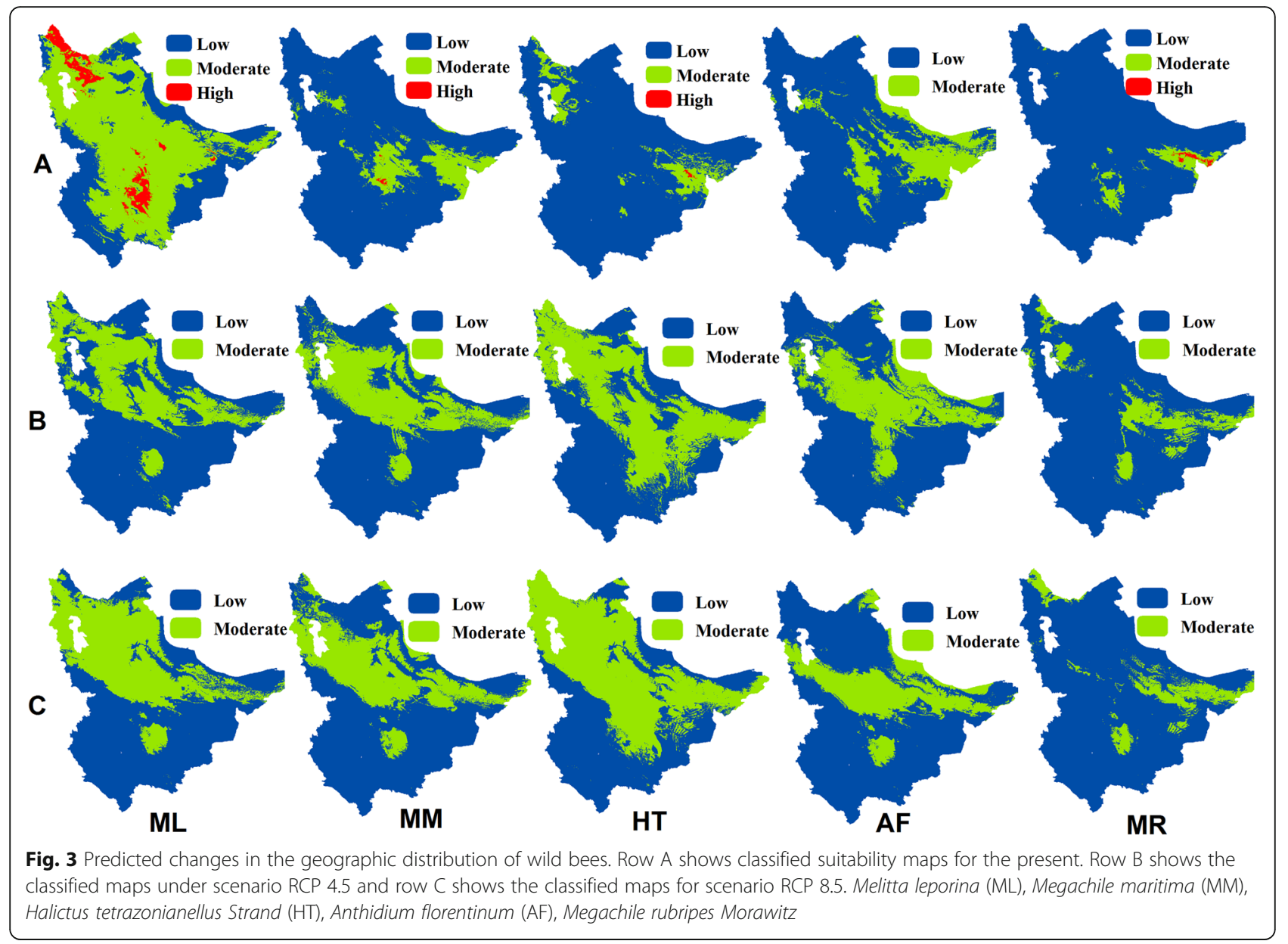

et al. 2016) because these species are more adaptable to cold weather and prefer lower-temperature habitats. In mountainous ecosystems, as the temperature rises, the bumblebees move to higher altitudes (Ploquin et al. 2013). For M. subnitida, Giannini et al. (2017) under scenario RCP 8.5 also found that the position of the best areas for this species will change and the possible distribution of this species will move to higher latitudes. Therefore, it seems that species that live in cold regions move to higher latitudes with a cooler climate as the temperature increases. This shift of wild bees to higher latitudes can jeopardize food security in our study area and deprive agricultural products of pollination by these bees. Decreased overlap between suitable areas of crops and wild bees due to climate change has been reported in various studies (Bezerra et al. 2019; Polce et al. 2014).

Our results also showed that with increasing temperature, the desired areas for the species under study will increase, and these species would have a possible wider range in the future. The result is different for Melitta leporina and the possible distribution ranges of this species will decrease with increasing temperature. Dew et al. (2019) reported that the range of suitable areas for Ceratina australensis under climate change scenarios in 2070 would increase due to climate changes. Rader et al. (2013) also showed that under the worst scenario of climate change, native bee pollination would increase by $4.5 \%$ by 2099 . Climate change has been reported as the major factor in reducing the population of bumblebee species in Britain (Williams et al. 2007) and declines in bees food in Europe (Dormann et al. 2008). However, Giannini et al. (2012) showed that the optimal habitat of bees decreased due to climate changes. This result has also been reported for several species of bumblebees (Suzuki-Ohno et al. 2020). In addition to species distribution, rising temperatures can also affect species richness. For example, Carrasco et al. (2020) showed that in North America, under scenarios RCP 4.5 and RCP 8.5, the richness of tomato pollinators decreased due to climate changes. Giannini et al. (2020) also showed that out of 216 species under study, $95 \%$ of them would experience a decrease in their populations due to climate change. It seems that the effects of climate change on the species distribution ranges are not constant and depending on the type of species and the study area, these effects can be different. Therefore, 
Table 5 Change in the predicted distribution of five wild bees under scenarios RCP 4.5 and RCP 8.5 based on random forest model. Melitta leporina (ML), Megachile maritima (MM), Halictus tetrazonianellus Strand (HT), Anthidium florentinum (AF), Megachile rubripes Morawitz

\begin{tabular}{|c|c|c|c|c|c|c|c|}
\hline Species & Scenario & High (Ha) & Proportion & Moderate (Ha) & Moderate (\%) & Low (Ha) & Low (\%) \\
\hline \multicolumn{8}{|l|}{ ML } \\
\hline & Current & 1943932 & $5.44 \%$ & 21339347 & $59.72 \%$ & 12448757 & $34.83 \%$ \\
\hline & RCP 4.5 & - & - & 11091199 & 31.03 & 24640787 & 68.95 \\
\hline & RCP 8.5 & - & - & 14167487 & 39.64 & 21564491 & 60.35 \\
\hline \multicolumn{8}{|l|}{ MM } \\
\hline & Current & 52833 & $0.14 \%$ & 4515188 & $12.63 \%$ & 31164039 & $87.21 \%$ \\
\hline & RCP 4.5 & - & - & 11273189 & 31.54 & 24458792 & 68.45 \\
\hline & RCP 8.5 & - & - & 11504298 & 32.19 & 24227761 & 67.80 \\
\hline \multicolumn{8}{|l|}{ HT } \\
\hline & Current & 40051 & $0.11 \%$ & 2938465 & $8.22 \%$ & 32753537 & $91.66 \%$ \\
\hline & RCP 4.5 & - & - & 15766892 & 44.12 & 19965121 & 55.87 \\
\hline & RCP 8.5 & - & - & 18698585 & 52.33 & 17033489 & 47.67 \\
\hline \multicolumn{8}{|l|}{ AF } \\
\hline & Current & - & - & 6950913 & $19.45 \%$ & 28781143 & $80.54 \%$ \\
\hline & RCP 4.5 & - & - & 11287744 & 31.58 & 24444311 & 68.41 \\
\hline & RCP 8.5 & - & - & 9105753 & 25.48 & 26626391 & 74.51 \\
\hline \multicolumn{8}{|l|}{ MR } \\
\hline & Current & 166248 & $0.46 \%$ & 1639611 & $4.58 \%$ & 33926212 & $94.94 \%$ \\
\hline & RCP 4.5 & - & - & 4597065 & 12.86 & 31134928 & 87.13 \\
\hline & RCP 8.5 & - & - & 3879527 & 10.85 & 31852527 & 89.14 \\
\hline
\end{tabular}

different species respond differently to climate change because of their body size and thermoregulatory ability (Rader et al. 2013), therefore, if species respond differently to climate change, so do agricultural products.

Although the range of species distribution will increase with increasing temperature, the quality of suitable areas will decrease in terms of climate because for all species under study we found that the high-suitability class disappeared under scenarios RCP 4.5 and RCP 8.5. Therefore, this study emphasizes more on the negative effects of climate change because for one species, these effects would reduce the suitable areas, and for the other four species, the increase in temperature would cause the loss of habitat quality in terms of climate. Therefore, studies that report an increase in wild bee habitat because of rising temperatures should also consider habitat quality changes. It is almost impossible for bees to adapt to climate change because climate change occurs so quickly and bees will have to migrate to higher latitudes or climatically suitable habitats or they will become extinct. In addition, climate change, along with the fragmentation of bee habitats, insecticides, and diseases, will increasingly reduce the population of these species. Different responses of insects and plants to climate change can cause temporal and spatial mismatch for affected species. Mismatches between plants and pollinators reduce pollination on farms by wild bees. If climate change alters the distribution ranges of wild bees in the future, farmers will be forced to use managed bees to pollinate their crops, which could incur additional costs.

The results of the uncertainty analysis showed that different models obtain different habitat suitability maps and as a result, there is significant uncertainty in the use of these models. For different species, the models used in this study obtained different estimates of habitat suitability classes. Therefore, this point should be considered in the species distribution modeling studies. To eliminate uncertainty between these models, the results of all models are usually ensembled to overcome the existing limitations (Jafarian et al. 2019). Using the ensemble method can lead to better predictions when the models have acceptable performance. In this study, because the random forest model showed higher performance than the other models, we preferred to investigate the possible effects of climate change on species distribution based solely on this model. The results of sensitivity analysis also showed that the number of environmental layers used to model the distribution of species has a significant effect on the results. This study showed that the removal of the most effective environmental layer from 
the habitat suitability modeling process led to changes in the area of high, moderate, and low suitability classes.

\section{Conclusions}

In general, three important conclusions can be drawn from this study: (1) The effects of climate change on different species are different and the increase in temperature mainly expands the distribution ranges of wild bees; (2) the increase in temperature will force wild bees to shift to higher latitudes. (3) There is significant uncertainty in the use of different models and the number of environmental layers used in the modeling of habitat suitability maps. Although increasing temperature increases the possible range of species distribution, it is also necessary to examine the effects of climate changes on the habitat quality of the species. For example, our results show that high-quality habitats may disappear despite expanding species distribution range. Therefore, in species distribution modeling under the climate change effects, it should be determined whether the increase in the distribution range of the species is accompanied by an increase in high-quality habitats for the species. The above conclusions warn ecologists that the northwestern regions of Iran will lose their high-quality habitats for wild bees in the future, and these species are likely to migrate to higher latitudes or neighboring countries. Therefore, it is suggested that farmers in these areas be aware of the effects of climate change on agricultural production and pay attention to the use of managed bees.

\section{Abbreviations \\ RCP: Representative concentration pathway scenario; AUC: Area under the curve; TSS: True skill statistic; SDM: Species distribution modeling; KL: Melitto leporina; MM: Megachile maritima; HT: Halictus tetrazonianellus Strand; AF: Anthidium florentinum; MR: Megachile rubripes Morawitz; GLM: Generalized linear models; MLR: Multiple logistic regression; GLR: Gaussian logistic regression; LR: Logistic regression; ANN: Artificial neural network; GAM: Generalized additive model; CART: Classification and regression tree model; NPMR: Non-parametric multiplicative regression; LRT: Logistic regression tree; RF: Random forest; BRT: Boosted regression tree}

\section{Acknowledgements}

Not applicable

\section{Code availability}

Code available on request from the authors only based on logical requests.

\section{Authors' contributions}

ER has written the paper and has done the modeling part of the analysis. ShB has reviewed the paper, helped to write, and interpreted the results. PD has reviewed the paper, edited grammar, and helped to respond to the paper's questions. The authors read and approved the final manuscript.

\section{Funding}

There are no financial conflicts of interest to disclose.

\section{Availability of data and materials}

Data are available on request from the authors only based on logical requests.

\section{Declarations}

Ethics approval and consent to participate

Not applicable

\section{Consent for publication}

Not applicable

\section{Competing interests}

On behalf of all authors, the corresponding author states that there is no conflict of interest.

\section{Author details}

${ }^{1}$ Environmental Sciences Research Institute, Shahid Beheshti University, Tehran, Iran. 'Department of Geography and the Environment, University of North Texas, Denton, USA

Received: 14 May 2021 Accepted: 26 July 2021

Published online: 14 August 2021

\section{References}

Barbet-Massin M, Jiguet F, Albert CH, Thuiller W. Selecting pseudo-absences for species distribution models: how, where and how many? Methods Ecol Evol. 2012;3(2):327-38.

Bezerra ADM, Pacheco Filho AJ, Bomfim IG, Smagghe G, Freitas BM. Agricultural area losses and pollinator mismatch due to climate changes endanger passion fruit production in the Neotropics. Agric Syst. 2019;169:49-57.

Bradter U, Kunin WE, Altringham JD, Thom TJ, Benton TG. Identifying appropriate spatial scales of predictors in species distribution models with the random forest algorithm. Methods Ecol Evol. 2013;4(2):167-74.

Carrasco L, Papeş M, Lochner EN, Ruiz BC, Williams AG, Wiggins GJ. Potential regional declines in species richness of tomato pollinators in North America under climate change. Ecol Appl. 2020:e02259.

Celary W. Biology of the solitary ground-nesting bee Melitta leporina (Panzer, 1799)(Hymenoptera: Apoidea: Melittidae). J Kansas Entomol Soc. 2006;79(2): 136-45.

Challinor AJ, Ewert F, Arnold S, Simelton E, Fraser E. Crops and climate change: progress, trends, and challenges in simulating impacts and informing adaptation. J Exp Bot. 2009;60(10):2775-89.

Christmann S, Aw-Hassan AA. Farming with alternative pollinators (FAP) —an overlooked win-win-strategy for climate change adaptation. Agric Ecosyst Environ. 2012:161:161-4.

Coope G. Insect faunas in ice age environments: why so little extinction. Extinction rates. 1995:55-74.

Cushman SA, Wasserman TN. Landscape applications of machine learning: comparing random forests and logistic regression in multi-scale optimized predictive modeling of American marten occurrence in northern Idaho, USA, in: Machine Learning for Ecology and Sustainable Natural Resource Management, Springer. 2018. p. 185-203.

Deutsch CA, Tewksbury JJ, Huey RB, Sheldon KS, Ghalambor CK, Haak DC, et al. Impacts of climate warming on terrestrial ectotherms across latitude. Proc Natl Acad Sci. 2008:105(18):6668-72.

Dew RM, Silva DP, Rehan SM. Range expansion of an already widespread bee under climate change. Global Ecology and Conservation. 2019;17:e00584

Dikmen F, Aytekin AM. Notes on the Halictus Latreille (Hymenoptera: Halictidae) fauna of Turkey. Turkish Journal of Zoology. 2011;35(4):537-50.

Dormann CF, Schweiger O, Arens P, Augenstein I, Aviron S, Bailey D, et al. Prediction uncertainty of environmental change effects on temperate European biodiversity. Ecol Lett. 2008;11(3):235-44.

Elith J, Leathwick JR. Species distribution models: ecological explanation and prediction across space and time. Annu Rev Ecol Evol Syst. 2009;40:677-97.

Elith J, Leathwick JR, Hastie T. A working guide to boosted regression trees. J Anim Ecol. 2008;77(4):802-13.

Fernández M, Hamilton H, Kueppers L. Characterizing uncertainty in species distribution models derived from interpolated weather station data. Ecosphere. 2013:4(5):1-17.

Giannini TC, Acosta AL, Garófalo CA, Saraiva AM, Alves-dos-Santos I, ImperatrizFonseca VL. Pollination services at risk: bee habitats will decrease owing to climate change in Brazil. Ecol Model. 2012;244:127-31.

Giannini TC, Maia-Silva C, Acosta AL, Jaffé R, Carvalho AT, Martins CF, et al. Protecting a managed bee pollinator against climate change: strategies for 
an area with extreme climatic conditions and socioeconomic vulnerability. Apidologie. 2017;48(6):784-94

Giannini TC, Costa WF, Borges RC, Miranda L, da Costa CPW, Saraiva AM, et al. Climate change in the Eastern Amazon: crop-pollinator and occurrencerestricted bees are potentially more affected. Reg Environ Chang. 2020; 20(1):1-12.

Guisan A, Edwards TC Jr, Hastie T. Generalized linear and generalized additive models in studies of species distributions: setting the scene. Ecol Model. 2002:157(2-3):89-100

Güler Y, Bursali B. Megachile maritima (KIRBY) ve Icteranthidium cimbiciforme (SMITH)(Hymenoptera: Megachilidae) Türleri Üzerinde Entomopalinolojik Bir Çalışma. Uludağ Arıcılık Dergisi. 2008:8(1):30-5.

Hegland SJ, Nielsen A, Lázaro A, Bjerknes AL, Totland Ø. How does climate warming affect plant-pollinator interactions? Ecol Lett. 2009;12(2):184-95.

Imbach P, Fung E, Hannah L, Navarro-Racines CE, Roubik DW, Ricketts TH, et al. Coupling of pollination services and coffee suitability under climate change. Proc Natl Acad Sci. 2017;114(39):10438-42.

Jafarian Z, Kargar M, Bahreini Z. Which spatial distribution model best predicts the occurrence of dominant species in semi-arid rangeland of northern Iran? Ecological Informatics. 2019;50:33-42.

Karlík P. Poschlod P. Soil seed-bank composition reveals the land-use history of calcareous grasslands. Acta Oecol. 2014;58:22-34.

Kerr JT, Pindar A, Galpern P, Packer L, Potts SG, Roberts SM, et al. Climate change impacts on bumblebees converge across continents. Science. 2015;349(6244): 177-80.

Kjøhl M, Nielsen A, Stenseth NC. Potential effects of climate change on crop pollination. Food and Agriculture Organization of the United Nations (FAO) 2011.

Klein A-M, Vaissiere BE, Cane JH, Steffan-Dewenter I, Cunningham SA, Kremen C, et al. Importance of pollinators in changing landscapes for world crops. Proc R Soc B Biol Sci. 2007;274(1608):303-13.

Kosicki JZ. Generalised additive models and random forest approach as effective methods for predictive species density and functional species richness. Environ Ecol Stat. 2020:27(2):273-92.

Memmott J, Craze PG, Waser NM, Price MV. Global warming and the disruption of plant-pollinator interactions. Ecol Lett. 2007;10(8):710-7.

Milano NJ, Iverson AL, Nault BA, SH MA. Comparative survival and fitness of bumblebee colonies in natural, suburban, and agricultural landscapes. Agric Ecosyst Environ. 2019;284:106594.

Miller J. Species distribution modeling. Geogr Compass. 2010:4(6):490-509.

Mohammadian H. Bees of Iran. Khatam (in Persian); 2003. p. 86

Naimi B, Araujo MB, Naimi MB, Naimi B, Araujo M. Package 'sdm'; 2016.

Ollerton J, Winfree R, Tarrant S. How many flowering plants are pollinated by animals? Oikos. 2011;120(3):321-6.

Pachauri RK, Allen MR, Barros VR, Broome J, Cramer W, Christ R, Church JA, Clarke L, Dahe Q, Dasgupta P. Climate change 2014: synthesis report. Contribution of Working Groups I, II and III to the fifth assessment report of the Intergovernmental Panel on Climate Change, Ipcc. 2014

Ploquin EF, Herrera JM, Obeso JR. Bumblebee community homogenization after uphill shifts in montane areas of northern Spain. Oecologia. 2013; 173(4):1649-60

Polce C, Garratt MP, Termansen M, Ramirez-Villegas J, Challinor AJ, Lappage MG et al. Climate-driven spatial mismatches between British orchards and their pollinators: increased risks of pollination deficits. Glob Chang Biol. 2014;20(9): 2815-28.

Pyke GH, Thomson JD, Inouye DW, Miller TJ. Effects of climate change on phenologies and distributions of bumblebees and the plants they visit. Ecosphere. 2016;7(3):e01267.

Rader R, Reilly J, Bartomeus I, Winfree R. Native bees buffer the negative impact of climate warming on honey bee pollination of watermelon crops. Glob Chang Biol. 2013;19(10):3103-10.

Rafferty NE. Effects of global change on insect pollinators: multiple drivers lead to novel communities. Current Opinion in Insect Science. 2017;23:22-7.

Rahimi A, Mirmoayedi A. Evaluation of morphological characteristics of honey bee Apis mellifera meda (Hymenoptera: Apidae) in Mazandaran (North of Iran). Tech J Eng Appl Sci. 2013;3(13):1280-4.

Rather TA, Kumar S, Khan JA. Multi-scale habitat selection and impacts of climate change on the distribution of four sympatric meso-carnivores using random forest algorithm. Ecol Process. 2020;9(1):1-17.

Renner IW, Elith J, Baddeley A, Fithian W, Hastie T, Phillips SJ, et al. Point process models for presence-only analysis. Methods Ecol Evol. 2015;6(4):366-79.
Samin N, Ghahari H, Bagriacik N. A faunistic study on leafcutting bees (Hymenoptera: Apoidea: Megachilidae) from some regions of Iran. Arquivos Entomolóxicos. 2015;14:193-200.

Sanjerehei MM. The economic value of bees as pollinators of crops in Iran. Annu Res Rev Biol. 2014;2957-64

Scaven VL, Rafferty NE. Physiological effects of climate warming on flowering plants and insect pollinators and potential consequences for their interactions. Current zoology. 2013;59(3):418-26.

Schweiger O, Biesmeijer JC, Bommarco R, Hickler T, Hulme PE, Klotz S, et al. Multiple stressors on biotic interactions: how climate change and alien species interact to affect pollination. Biol Rev. 2010:85(4):777-95.

Sirois-Delisle C, Kerr JT. Climate change-driven range losses among bumblebee species are poised to accelerate. Sci Rep. 2018;8(1):1-10.

Stocker TF, Qin D, Plattner GK, Tignor MM, Allen SK, Boschung J, Nauels A, Xia Y, Bex V, Midgley PM. Climate Change 2013: The physical science basis contribution of working group I to the fifth assessment report of IPCC the intergovernmental panel on climate change. 2014.

Strobl C, Boulesteix AL, Zeileis A, Hothorn T. Bias in random forest variable importance measures: illustrations, sources, and a solution. BMC bioinformatics. 2007:8(1):1-21.

Suzuki-Ohno Y, Yokoyama J, Nakashizuka T, Kawata M. Estimating possible bumblebee range shifts in response to climate and land cover changes. Sci Rep. 2020;10(1):1-12.

Takkis K, Tscheulin T, Petanidou T. Differential effects of climate warming on the nectar secretion of early-and late-flowering Mediterranean plants. Front Plant Sci. 2018;9:874.

Talebi KS, Sajedi T, Pourhashemi M. Forests of Iran, in A Treasure From the Past, a Hope for the Future, Springer; 2014

Tarkesh M, Jetschke $\mathrm{G}$. Comparison of six correlative models in predictive vegetation mapping on a local scale. Environ Ecol Stat. 2012;19(3):437-57.

Valavi R, Elith J, Lahoz-Monfort JJ, Guillera-Arroita G. Modelling species presenceonly data with random forests. bioRxiv. 2020

Viana BF, Boscolo D, Mariano Neto E, Lopes LE, Lopes AV, Ferreira PA, et al. How well do we understand landscape effects on pollinators and pollination services? J Pollination Ecol. 2012. p. 7

Williams PH, Araújo MB, Rasmont P. Can vulnerability among British bumblebee (Bombus) species be explained by niche position and breadth? Biol Conserv. 2007;138(3-4):493-505.

Wirtz P, Kopka S, Schmoll G. Phenology of two territorial solitary bees, Anthidium manicatum and A. florentinum (Hymenoptera: Megachilidae). J Zool. 1992; 228(4):641-51.

Yurk BP, Powell JA. Modeling the evolution of insect phenology. Bull Math Biol. 2009;71(4):952-79.

Zurell D, Franklin J, König C, Bouchet PJ, Dormann CF, Elith J, et al. A standard protocol for reporting species distribution models. Ecography. 2020;43(9): $1261-77$.

\section{Publisher's Note}

Springer Nature remains neutral with regard to jurisdictional claims in published maps and institutional affiliations.

Ready to submit your research? Choose BMC and benefit from:

- fast, convenient online submission

- thorough peer review by experienced researchers in your field

- rapid publication on acceptance

- support for research data, including large and complex data types

- gold Open Access which fosters wider collaboration and increased citations

- maximum visibility for your research: over $100 \mathrm{M}$ website views per year

At BMC, research is always in progress.

Learn more biomedcentral.com/submissions 